\title{
Hand-Assisted Laparoscopic Right Colectomy: Is It Useful?
}

\author{
Hungdai Kim \\ Department of Surgery, Gastrointestinal Cancer Center, Kangbuk Samsung Medical Center, Seoul, Korea
}

See Article on Page 11-17

These days, minimally invasive surgery (MIS) has become the standard surgical procedure in Korea for patients with colon cancer. Among various techniques for MIS, conventional laparoscopic surgery (CLS) has gained in popularity. Furthermore, highquality articles regarding outcomes of MIS for colorectal cancer treatment that were written by Korean surgeons have been published in leading medical journals $[1,2]$. On the other hand, hand-assisted laparoscopic surgery (HALS) is still infrequently implemented in Korea because its position as a surgical option is still unsettled.

In the literature, whether or not the HALS procedure is useful for a right colectomy is a subject of controversy. $\mathrm{Ng}$ et al. [3] reported that a HALS right colectomy did not confer additional advantages over a laparoscopic right colectomy in terms of clinical, operative or oncological outcomes. For this reason, the routine use of the hand-assisted laparoscopic technique for treating right colonic cancers cannot be recommended. Vogel et al. [4] conduct a similar study, and the short-term outcomes of a HALS and a CLS right colectomy were similar. However, they arrived at a different conclusion in that they recommended that the decision to perform a HALS or a CLS right colectomy should be based on the surgeons' preference and not on the perception that one technique was preferable to the other.

In this present study, the HALS group included more advanced cancers than the CLS group did. Thus, the authors' conclusions were similar to those of $\mathrm{Ng}$ et al. [3] in that the HALS technique had an advantage for treating complex and extensive cancers only [5]. From a CLS surgeon's point of view, it was only natural for CLS surgeons to come to this conclusion. CLS surgeons are used

Correspondence to: Hungdai Kim, M.D.

Department of Surgery, Kangbuk Samsung Medical Center, 29 Saemunan-ro, Jongno-gu, Seoul 110-746, Korea

Tel: +82-2-2001-8541, Fax: +82-2-2001-2131

E-mail: hungdai.kim@samsung.com

(C) 2014 The Korean Society of Coloproctology

This is an open-access article distributed under the terms of the Creative Commons Attribution NonCommercial License (http://creativecommons.org/licenses/by-nc/3.0) which permits unrestricted noncommercial use, distribution, and reproduction in any medium, provided the original work is properly cited. to performing CLS, so they feel no need to conduct HALS. However, the similar clinical outcomes for CLS and HALS do not mean that HALS is an unnecessary procedure; rather, it means that surgeons can choose the procedure they like. Thus, although I agree with the authors' conclusion in this present study, if the true value of a HALS right colectomy is to be determined, a comparative, prospective study should be conducted on the two groups under equal conditions.

\section{REFERENCES}

1. Park JS, Choi GS, Park SY, Kim HJ, Ryuk JP. Randomized clinical trial of robot-assisted versus standard laparoscopic right colectomy. Br J Surg 2012;99:1219-26.

2. Kang SB, Park JW, Jeong SY, Nam BH, Choi HS, Kim DW, et al. Open versus laparoscopic surgery for mid or low rectal cancer after neoadjuvant chemoradiotherapy (COREAN trial): short-term outcomes of an open-label randomised controlled trial. Lancet Oncol 2010;11:637-45.

3. Ng LW, Tung LM, Cheung HY, Wong JC, Chung CC, Li MK. Hand-assisted laparoscopic versus total laparoscopic right colectomy: a randomized controlled trial. Colorectal Dis 2012;14:e612-7.

4. Vogel JD, Lian L, Kalady MF, de Campos-Lobato LF, Alves-Ferreira PC, Remzi FH. Hand-assisted laparoscopic right colectomy: how does it compare to conventional laparoscopy? J Am Coll Surg 2011;212:367-72.

5. Bae SK, Kim CN, Park JS, Choi YJ, Lee MK, Cho BS, et al. The role of hand-assisted laparoscopic surgery in right hemicolectomy for right-sided colon cancer. Ann Coloproctol 2014;30:11-7. 